\title{
Oligomethylphenylsiloxanes and methylphenylsiloxane resins: preparation, use and compositions
}

\author{
(C) Andrey M. Kontorov, ${ }^{*+}$ and Alexander Yu. Glushchenko \\ "Rus Injection". Saltykovskaya St., House 37, Building 1, Room 1. \\ Moscow, 111672.Russia.E-mail:ankont2@yandex.ru
}

\begin{abstract}
*Supervising author; ${ }^{+}$Corresponding author Keywords: methylphenylsiloxane resins, oligomethylphenylsiloxanes.
\end{abstract}

\begin{abstract}
A review is given on the class of organosilicon compounds of oligomethylphenylsiloxanes and methylphenylsiloxane resins. The review includes the main chemical methods for producing oligomethylphenylsiloxanes and methylphenylsiloxane resins, the main reactions, occurring with the participation of oligomethylphenylsiloxanes, areas of application of oligomethylphenylsiloxanes. The review provides compositions of oligomethylphenylsiloxanes. The review consists of 50 literature sources.

To obtain oligomethylphenylsiloxanes, several production methods are used. Basically, this is a method of hydrolytic co-condensation of the corresponding organochlorosilanes with subsequent catalytic rearrangement of the hydrolysis products, a heterofunctional condensation reaction, or exchange decomposition. High-polymer organosilicon compounds are obtained as a result of synthesis from alkyl and aryl-substituted esters of orthosilicic acid or from alkyl and arylsilane chlorides, which upon hydrolysis form hydroxy derivatives (silanols), condensing into resins when heated. At present, new fields of application of oligomethylphenylsiloxanes have appeared. This is the creation of radiation-resistant materials, heat-resistant paints, protection of concrete structures, heat-resistant fiberglass.
\end{abstract}

\section{References}

[1] Le Fu Shoan. Synthesis of methacrylate-containing oligosilsesquioxane acidohydrolytic polycondensation in methacrylic monomers. Dissertation for a scientific degree, candidate of chemical sciences. Moscow. 2017. (russian)

[2] Oligoorganosiloxanes. Properties, receipt, application. Moscow: Chemistry. 1975. (russian)

[3] New Heat-Proof. Methylphenylsiloxane Resins and High Temperature Resisting Enamels on Their Basis, O.G. Ryzhova, A.M. Kontorov, A.N. Polivanov, R.S. Mirgazitova and A.I. Katanaev. International Research Journal of Pure \& Applied Chemistry 4(5): 2014. 520-530p.

[4] A. Vorobiev. Organosilicon resins. Components and technologies. 2004. No.2.

[5] Andrey M. Kontorov. New methylphenylsiloxane resin based on alkoxysilanes. Butlerov Communications. 2019. Vol.59. No.7. P.142-149. DOI: 10.37952/ROI-jbc-01/19-59-7-142

[6] Patent No. 2495895 Cl "Heat-resistant enamel", dated 10.05.2012, A.I. Katanaev, R.S. Mirgazitova, A.N. Polivanov, O.G. Ryzhova, A.M. Kontorov

[7] L.M. Khananashvili, K.A. Andrianov. Technology of organoelement monomers and polymers. Moscow: Chemistry. 1983. (russian)

[8] M.V. Sobolevsky, O.A. Muzovskaya, G.S. Popeleva. Properties and fields of application of organosilicon products. Moscow: Chemistry. 1975. (russian)

[9] D. Pinkert, C. Limberg. Iron Silicates, Iron-Modulated Zeolite Catalysts, and Molecular Models Thereof. European Journal. 2014. No.30. P.9167-9175.

[10] Electric wire covering material. Patent of China CN104059330. 2014. Zhang, Haoliang.

[11] Polysiloxane-modified thermoplastic material and its preparation method. Patent of China, CN102924793. 2013. Li, Yanmin.

[12] Silane coupler-modified epoxy resin adhesive for optical fiber. Patent of China CN102766432. 2012. Cao, Xianglai; Kong, Qingru; Qiao, Yi.

[13] Polycarbonate resin composition with good flame retardancy and light stability and use for LCD backlight. Patent of United States US 20090239975. 2009. Jung, Hyuk Jin; Lim, Jong Cheol; Lee, Sang Hwa; Kim, Jong Yeu. 
[14] Primer and finishing coating for high temperature exhaust pipe. Patent of China CN101531867. 2009. Zhu, Hongjiang.

[15] Organic silicone potting materials with high hot moisture and weather resistance for electronics. Patent of China CN101016446. 2007. Su, Junliu; Tang, Shengshan; Li, Jiazhong.

[16] Environment-friendly flameproof composite paints. Patent of China CN1995246. 2007. Yao, Qian; Yao, Xin; Yao, Huiwo.

[17] Zharostoikie Teplostoikie Pokrytiya, Tr. Vses. Soveshch., 4th, Conference. 1969. Pages372-9.

[18] Forming hard organopolysiloxane coatings on plastic materials Mar 19, 1971. Patent of FR 2044184

[19] Polymer Degradation and Stability. Journal. 1993. Vol. 41. Iss.3. P.319-22.

[20] Effect of $\gamma$-radiation on sorption characteristics of poly(methylphenylsiloxane) films, Eremina, N.S.; Minakova, T.S.; Komissarova, V.N. Khimiya Vysokikh Energiyi. 1988. Vol.22. Iss.3 P.215-17.

[21] Effect of protons on siloxanes containing methyl and phenyl groups, Pankratova, L.N.; Zheleznikova, M.V. Zhurnal Fizicheskoi Khimii. 1978. Vol.52. Iss.9. P.2411-13.

[22] Single-ply quartz fabric-reinforced organosilicon laminate. V.F. Simonov, F.F. Urmansov, V.E. Bitkin, A.N. Shmatov, O.N. Sukhikh, Jun 20, 2003. Patent of RU 2206454

[23] Method for preparing foamable organosilicon compositions Minasyan, Ruben Mkrtichovich; Semenkova, Nataliya Jurievna; Makarenko, Igor Anatolievich; Polivanov, Alexandr Nikolaevich; Belyaev, Spartak Timofeevich; Kozodaeva, Nataliya Mikhailovna; Kozodaeva, Marina Mikhailovna; Gulko, Peter; Perevozchikov, Sergei Alexandrovich; Shvetsov, Ivan Konstantinovich. Obschestvennoe Obiedinenie "Eurasian Physical Society", Russia. Jul 22, 1999. Patent of WO 9936463

[24] High temperature resistant powder paint, Xia, Baiqing, Jul 6, 2018. Patent of CN 108250949

[25] Environmentally friendly water-based fire retardant paint, Cheng, Yao, Mar 25, 2015. Patent of CN 104448976

[26] Siloxane-containing soil-resistant outdoor acrylic dispersion paint, Adamec, Jozef; Drobna, Pavlina; Hajkova, Vera; Piskla, Stefan, Mar 18, 1992. Patent of CS 276053

[27] Antiburning paint for foundry molds and cores for steel castings weighing from $500 \mathrm{~kg}$ to 3-5 tons. I.G. Ratush, L.V. Lokotkov, Yu.I. Khudobin, G.A. Kaplunovskii, A.D. Nikiforov, N.P. Kharitonov, G.P. Shlomin, V.F. Palkin, Kanina, Oct 30, 1982. Patent of SU 926842

[28] Surface treatment method for increasing durability of concrete structures through reactive selfhealing concrete surface modifiers, marble protective material, and chemical-resistant cross-section repair of high-tensile short nanofibers, Kim, Yu Seok, Mar 20, 2020. Patent of KR 2091753

[29] Compositions for impregnating concrete. V.A. Sviderskii, Yu.I. Chop, A.S. Volkov, I.V. Arshinnikov, P.S. Borsuk, M.Yu. Chop, O.D. Tsibenko, Mar 23, 1990. Patent of SU 1551706

[30] Composition for impregnation of concrete. V.A. Sviderskii, I.I. Chirikalov, E.A. Pashchenko, V.A. Roslyakova, Oct 30, 1987. Patent of SU 1348324

[31] Anticorrosion coatings for the protection of reinforcement. N.N. Kruglitskii, E.V. Terlikovskii. Stroitel'nye Materialy i Konstruktsii. Journal. 1981. Iss.1. P.9-10.

[32] Organosilicon polymer cements based on magnesium oxide. V.P. Lyutyi, N.A. Sokolova, Kharitonov N.P., P.F. Rumyantsev. Issled. Obl. Fiz. Khim. Kauch. Rezin Conference. 1975. P.209-11.

[33] Organosilicon protective coatings. V.I. Glubokii, A.I. Verzal, E.E. Zhilinskaya, A.I. Shevchenko. Sint. Prir. Polim. Mater. Conference. 1974. P.110-19.

[34] Concrete mixture. V.M. Moskvin, V.G. Batrakov, N.F. Zhigulev, E.I. Guseinov, Yu.L. Balukov, L.E. Kalliopin, Sep 27, 1973. Patent of SU 398588

[35] Manufacture of durable heat-resistant articles from fiberglass-reinforced plastics. M.Yu. Rusin, T.A. Pashutina, T.V. Sal'nikova, V.F. Sokolov, V.V. Vasilenko, L.P. Muzhanova, Dec 27, 2005. Patent of $R U 2266928$

[36] High temperature resistant polymer material. Zhang, Zusen, May 21, 2019. Patent of CN 109776915

[37] Heat-insulating self-cleaning eco-friendly coating, Liu, Feng; Liu, Wenhui, Jun 18, 2019. Patent of CN 109897485

[38] Effect of cure conditions on mechanical and thermal properties of siloxane-modified phenolic resins and composites. A. Tregub, L. Inglehart, C. Pham, R. Friedrich. International SAMPE Technical Conference, Composites for the Real World. 1997. Vol.29. P.787-799.

[39] Automotive brake alloy material with high wear resistance, toughness, high-temperature oxidation and corrosion resistances, Lv, Lingxia, Jun 12, 2013. Patent of CN 103146131

[40] Polyoxyalkylene siloxane copolymers with antistatic properties and their application to fiberglass insulation and other substrates. Lind, Eric J.; Fouts, Christine S., Sep 11, 2009. Patent of WO 2009111221 
OLIGOMETHYLPHENYLSILOXANES AND METHYLPHENYLSILOXANE RESINS: PREPARATION...

[41] Curable organopolysiloxane composition, optical semiconductor element sealant, and optical semiconductor device. Yoshitake, Makoto; Enami, Hiroji; Kato, Tomoko; Terada, Masayoshi, Feb 12, 2013. Patent of US 8373286

[42] Curable granular silicone composition and method for preparing same. Yamazaki, Ryosuke; Imaizumi, Toru; Ozaki, Kouichi, Sep 1, 2016. Patent of WO 2016136243

[43] Thermally conducting silicone grease composition. Ichiroku, Nobuhiro; Kizaki, Hiroaki; Uchida, Osamu, May 16, 2016. Patent of JP 2016079204

[44] Motor lubricating oil wear-resistant composition. Fan, Xiangku, Sep 17, 2014. Patent of CN 104046448i

[45] An adhesive composition and an adhesive film obtained therefrom. Chen, Liang, May 31, 2018. Patent of WO 2018094735

[46] Coating composition for bioprotection of wood. Katanaev, A.I.; Mirgazitova, R.S., Dec 10, 2009. Patent of RU 2375399

[47] Process for preparing styrenic thermoplastic resin. Ko, Young; Choi, Sung Muk; Oh, Won Seok, Dec 1, 1999. Patent of $K R 232700$

[48] Enamel composition for production of fire-resistant intumescent coatings. A.G. Zhuchenko, N.G. Zhuchenko; O.N. Zhuchenko, Jan 10, 2002. Patent of RU 2177973

[49] Composition for electric insulation. Gureva, Irina G., Oct 7, 1992. Patent of SU 1768032

[50] Abrasive composition. P.S. Kislyi, Yu.V. Dzyadykevich, E.N. Kal'ba, V.I. Pritula, O. Nagailo, Aug 23, 1982. Patent of SU 952934I 